\section{Síndrome de cola de caballo secundario a tuberculosis vertebral}

\author{
A cauda equina syndrome secondary to \\ vertebral tuberculosis
}

Rachid Bouchentouf'
Bouchentouf R. Síndrome de cola de caballo secundario a tuberculosis vertebral. 202I;34(I): 49.

https://doi.org/10.36393/spmi.v34i1.587

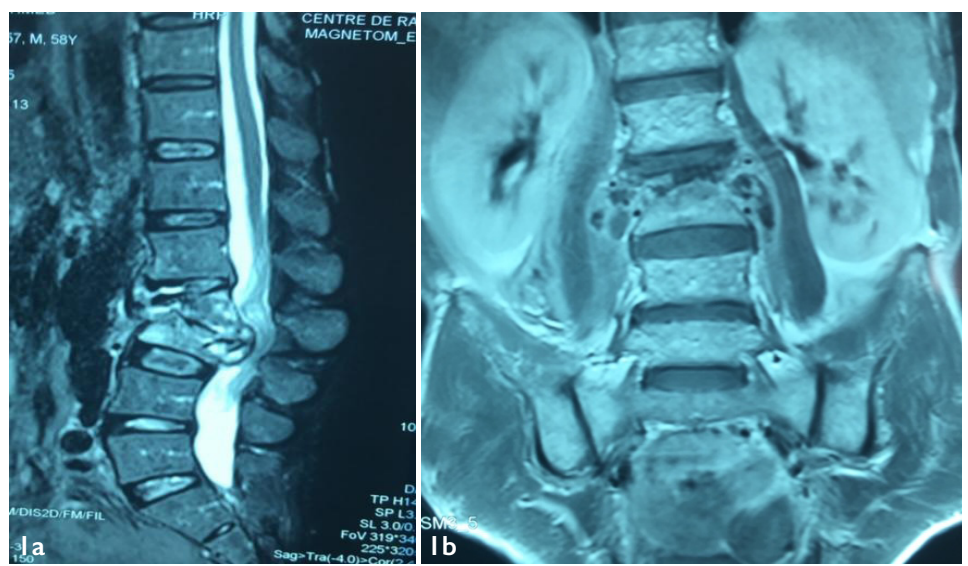

Varón de 52 años de edad, gran fumador, sin antecedentes de traumatismo, presentaba desde hace 2 meses lumbalgias irradiadas a la cara anterior de los muslos, refractarias a los analgésicos. Consultó por debilidad de los miembros inferiores y trastornos de los esfínteres (incontinencia anal y vesical) en la última semana. El examen mostró una paresia de los cuádriceps y una hipostesia en silla de montar. La RMN evidenció una lesión disco vertebral y compresión de L2-L3 con colección de partes blandas comprimiendo las raíces de la cola del caballo (Figuras 1a y 1b) De los exámenes auxiliares, lo relevante fue hemoglobina 9,5 g/ dl y proteína C reactiva $35 \mathrm{mg} / 1$, PPD $15 \mathrm{~mm}$; ELISA-VIH negativo y radiografía de tórax normal. La cirugía evacuó los abscesos paravertebrales, la exéresis de tejido necrótico y la descompresión neurológica. El examen histológico reveló la presencia de granulomas con células epitelioides y necrosis caseosa. Se inició tratamiento antituberculoso de 9 meses de duración según el protocolo 2RHZE/7RH, más inmovilización por un corsé enyesado. La evolución clínica fue buena con desaparición progresiva de los trastornos neurológicos.

I Servicio de neumología. Hospital Militar Avicena, Marrakech, Marruecos.
El síndrome de cola de caballo es una entidad poco frecuente provocado por la compresión de las raíces nerviosas entres L2-S5. Puede dejar graves secuelas si no es diagnosticado y tratado de forma precoz. La causa más frecuente es la hernia discal; sin embargo, la espondilodiscitis tuberculosa (mal de Pott) puede ser responsable de la deformidad de la columna vertebral y complicaciones neurológicas. La RMN es el método de elección para el diagnostico de la tuberculosis vertebral y el tratamiento es principalmente médico. En caso de síndrome de cola de caballo, la cirugía permite la descompresión medular y recuperación progresiva del déficit neurológico.

\section{REFERENCIAS BIBLIOGRÁFICAS}

I. Jain AK, Kumar J. (2013) Tuberculosis of spine: neurological deficit. Eur Spine J. 2013; 22 (Suppl 4):624-33.

2. Qureshi A, Sell P. Cauda equina syndrome treated by surgical decompression. Eur Spine J. 2007; 16:2143-5I.

\section{CORRESPONDENCIA:}

Rachid Bouchentouf

bouchentouf_rachid@yahoo.fr

Fecha de recepción: 12.02 .2021 .

Fecha de aceptación: 20-02-202I. 